\title{
Some aspects of the deep abyssal overflow between the middle and southern basins of the Caspian Sea
}

5 Javad Babagoli Matikolaei ${ }^{1}$, Abbas Ali AliAkbbari Bidokhti ${ }^{2}$, and Maryam Shiea ${ }^{3}$

${ }^{1}$ Graduate in Physical Oceanography, Institute of Geophysics, University of Tehran, Tehran, Iran.

${ }^{2}$ Institute of Geophysics, University of Tehran, Tehran, Iran.

${ }^{3}$ Faculty of Marine Science and Technology, Science and Research Branch, Islamic Azad University, Tehran, Iran.

10 Correspondence to: J. Babagoli Matikolaei (javadbabagoli@ut.ac.ir)

Abstract. This study investigates the deep gravity current between the middle and southern Caspian Sea basins, caused by density difference of deep waters. Oceanographic data, numerical model and dynamic models are used to consider the structure of this Caspian Sea abyssal overflow. The CTD data are obtained from UNESCO, and the three-dimensional ocean model COHERENS results are used to study the abyssal currents in the southern basin of the Caspian Sea.

The deep overflow is driven by the density difference mainly due to the temperature difference between the middle and southern basins especially in winter. For this reason, water sinks in high latitudes and after filling the middle basin it overflows into the southern basin. As the current passes through the Absheron Strait (or sill), we use an analytic model for the overflow gravity current with inertial and frictional effects to consider its structure. The dynamical characteristics of this deep baroclinic flow are investigated with different initial and boundary conditions. The results show that after time passes, the flow adjusts itself, moving as a deepening gravity driven topographically trapped current. This flow is considered for different seasons and its velocity and width are obtained. Because of the topography of the Southern Caspian basin, the flow is trapped after the sill; thus, another simple dynamical model of the overflow, based on potential vorticity conservation similar to that of Bidokhti and Ezam (2009) but with the bottom friction included, is used to find the horizontal extent of the outflow from the western coast. The result of this model shows that the Rossby length (deformation radius) of the flow decreases when drag coefficient increases. Because of the importance of the overflow in deep water ventilation, a simple dynamical model of the boundary currents based on the shape of strait is used to estimate typical mass transport and flushing time which is found to be about 15 to 20 years for the southern basin of the Caspian Sea. This time scale is important for the possible effects of pollutions due to oil exploration on the ecosystem of this water body.

30 Keywords: Overflow, dynamical model, trapped baroclinic bottom current, Caspian Sea abyssal flow. 
Ocean Sci. Discuss., doi:10.5194/os-2016-87, 2017

Manuscript under review for journal Ocean Sci.

\section{Introduction}

Baroclinic flows play important roles in ocean and sea circulations, especially in deep waters of the ocean. Because these currents are important in deep water ventilations of the oceans, they have an integral role in thermocline circulation. Vertical ocean circulation that is created by density differences and controlled by changes in surface temperature and salinity is known as thermohaline circulation. A driving mechanism for the circulation is the cooling of surface waters at high latitudes and consequent formations of deep waters by sinking the cooled salty water masses (Fogelqvist et al., 2003).

Cooling in polar seas (Dickson et al., 1990) and evaporation in marginal seas (Baringer and Price, 1997) cause dense waters that sink to form deep water masses. For example, dense water from the deep convective regions of the North Atlantic produces a signature of the thermohaline overturning circulation that can be seen as far away as the Pacific and Indian

10 oceans (Girton et al., 2003). In the global sense, bottom-trapped currents play an integral role in thermohaline circulation and are a vehicle for the transport of heat, salt, oxygen and nutrients over great distances and depths. The ability of abyssal flows to transport and deposit sediments is also of geological interest (Smith, 1975). As thermohaline circulation causes ventilation of deep ocean water, it is important not only in open seas and ocean but also in semi-closed and closed basins ventilations. Study of thermohaline dynamics and circulation has been of interest to different scientists as climate researchers. The

15 dynamics of such dense currents on slopes have been modelled in the past both theoretically and experimentally starting with Ellison and Turner (1959) and Britter and Linden (1980), and a review on gravity currents can be found in Griffiths (1986). Bidokhti and Ezam (2009) presented a simple dynamical model of the outflow from the Persian Gulf based on potential vorticity conservation to find the horizontal extent of the outflow from the coast.

The Caspian Sea, the world's largest inland enclosed water body, consists of three basins namely northern (shallow, mean

20 depth of about $10 \mathrm{~m}$ and covering $80000 \mathrm{~km}^{2}$ ), the middle (rather deep, with mean depth of about $200 \mathrm{~m}$, maximum depth $788 \mathrm{~m}$ and covering $138000 \mathrm{~km}^{2}$ ) and the southern (deep, with a mean depth of $350 \mathrm{~m}$, maximum depth $1025 \mathrm{~m}$ and covering $164840 \mathrm{~km}^{2}$ ) and is located between $36.5 \mathrm{~N}$ and 47.2N, and 46.5E and 54.1E (Aubrey et al., 1994; Aubrey, 1994). The bathymetric levels vary largely over this sea (Ismailova, 2004, Figure 1). The northern basin, after a sudden depth transition at the shelf edge, reaches the middle one. The middle and southern basins are divided by the Absheron sill or strait

25 (with maximum depth of $180 \mathrm{~m}$ ). The western slopes of the two deeper basins are fairly steep compared to the eastern slope (Gunduz and Özsoy, 2014).

The main aims of our work are interpretations and discussions of the abyssal flows in the southern Caspian Sea basin. For this reason, we used CTD data and simulations of a numerical model. Firstly, we explain why abyssal circulation occurs in the Caspian Sea, and then discuss the structure of the outflow (overflow) from the middle to the southern Caspian Sea over

30 the Absheron sill. In this study an analytical model for the overflow gravity current over the Absheron sill, with inertial and frictional effects, is then presented. After the flow passes over the Absheron sill, we present a new model for the structure of this flow using another analytical model based on potential vorticity conservation, similar to that of Bidokhti and Ezam 
Ocean Sci. Discuss., doi:10.5194/os-2016-87, 2017

Manuscript under review for journal Ocean Sci.

Published: 11 January 2017

(c) Author(s) 2017. CC-BY 3.0 License.

Discussions

(c) $\underset{\mathrm{BY}}{(i)}$

(2009) but the bottom friction is included. We then calculate values of mass transport, flushing times, and discuss the pathway of gravity current in southern Caspian Sea basin.

\section{Data used and results}

\section{$5 \quad 2.1$ Observational data}

The CTD data are obtained from UNESCO Atomic Energy International Agency, for summer 1996 (Figure 1). Vertical profiles of temperature, $T$, salinity, $S$ and sigma- $T$, for the northern, middle, and southern Caspian Sea basins, show differences in temperature, salinity and sigma- $T$ between these basins. Figure 2 shows typical vertical profiles of $T, S$ and sigma- $T$ in these basins (points a and $\mathrm{b}$ in Figure 1 right). Due to the density difference between the middle and southern

10 basins, dense current crosses the Absheron sill. The cross-section of sigma- $T$ shows that the abyssal gravity current moves from middle to southern basin (Figure 3). Not only in the Strait of Absheron are sigma- $T$ contour gradients obvious but also there are contour gradients in southern basin, indicative of the northern overflow. Due to the limited observational data, more extensive measurements and high resolution data are required to find the outflow structure and determine the analytical model parameters. For this reason, numerical model results have been used to do further analyses and also acquire the parameters of the overflow for the analytical model.
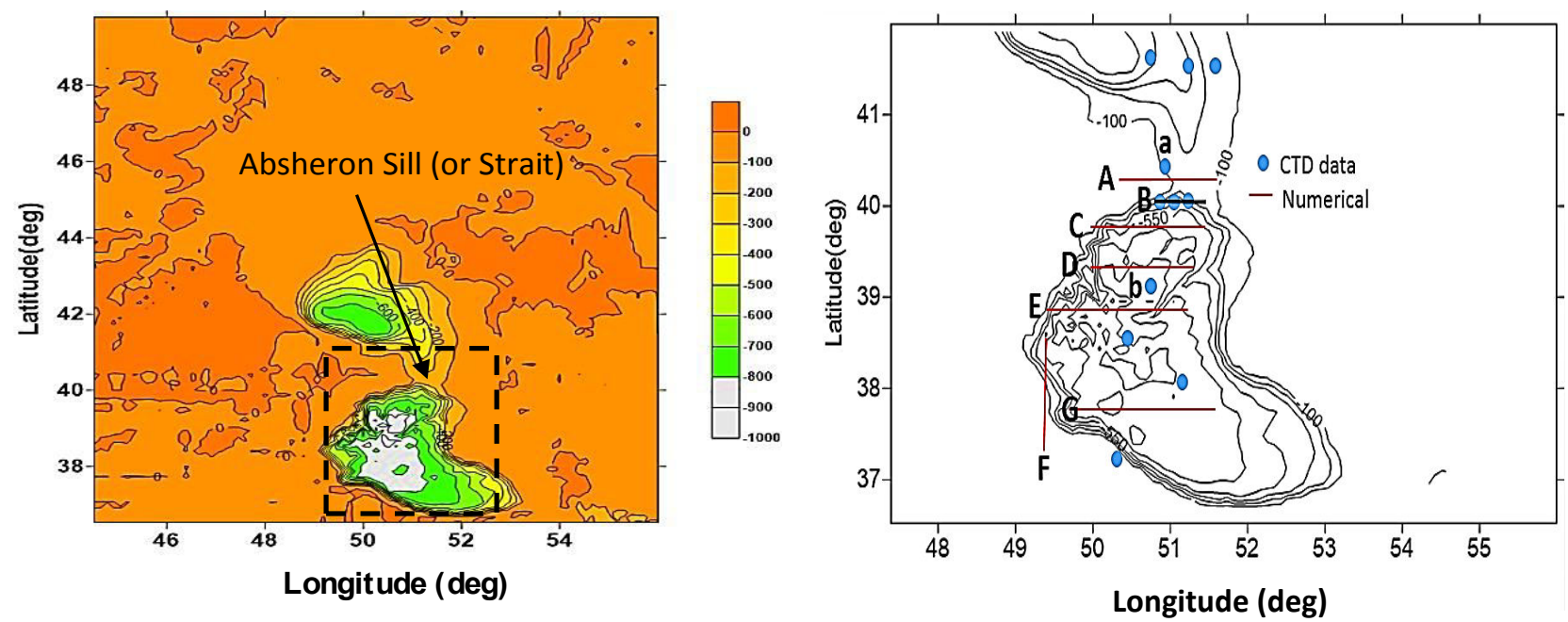

Figure 1: Scheme of the Caspian Sea and locations of CTD measurements, the geographic position of transects (right), and topography of the basins, showing the Absheron sill (left). 
Ocean Sci. Discuss., doi:10.5194/os-2016-87, 2017

Manuscript under review for journal Ocean Sci.

Published: 11 January 2017

(c) Author(s) 2017. CC-BY 3.0 License.
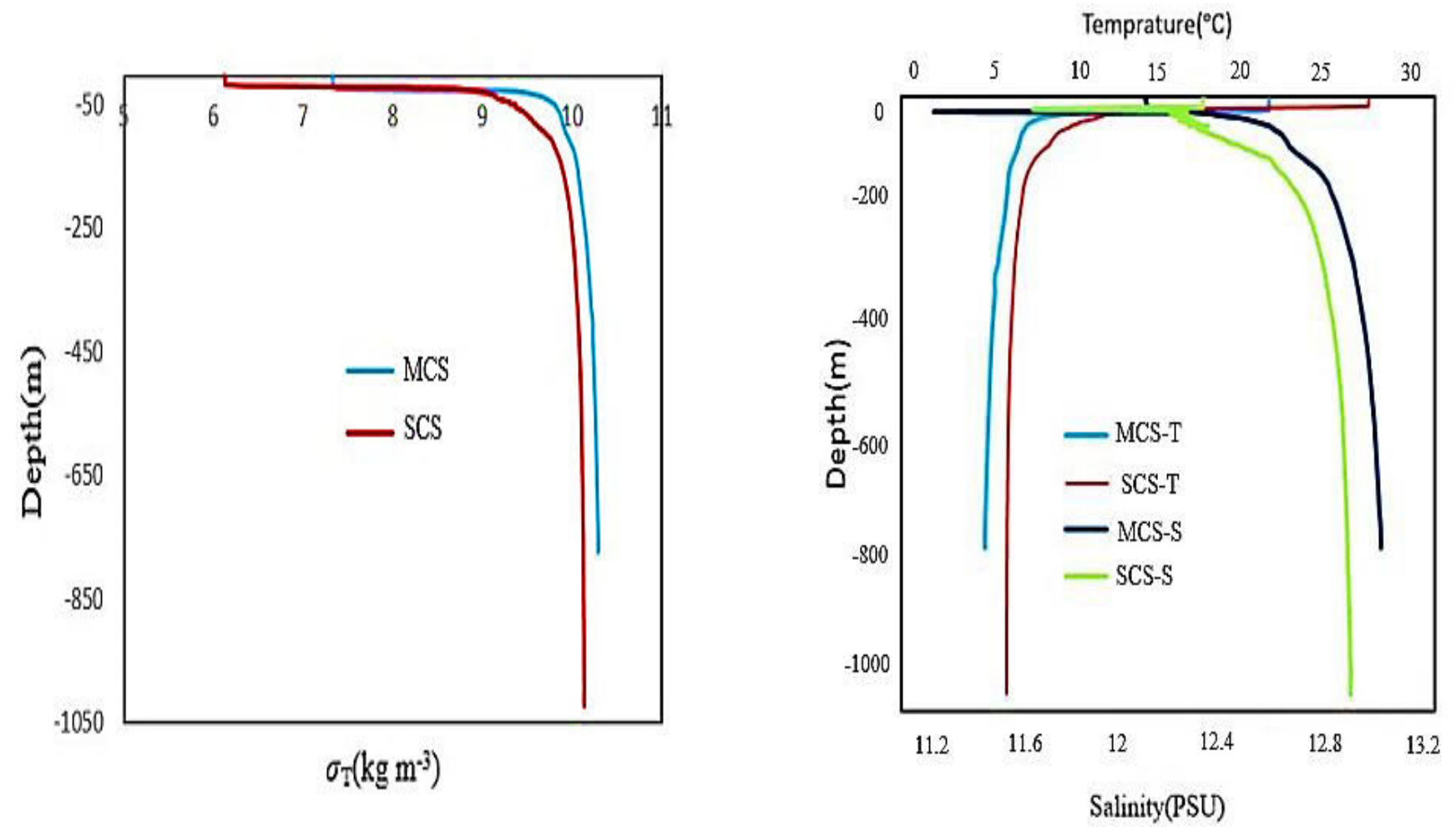

Figure 2: Comparison Salinity, $S$ and temperature, $T$ (right), and sigma- $T$ (left) profiles between points a, in middle (MCS) and $b$, in southern (SCS) Caspian Sea basins (Figure 1 right).

5

10
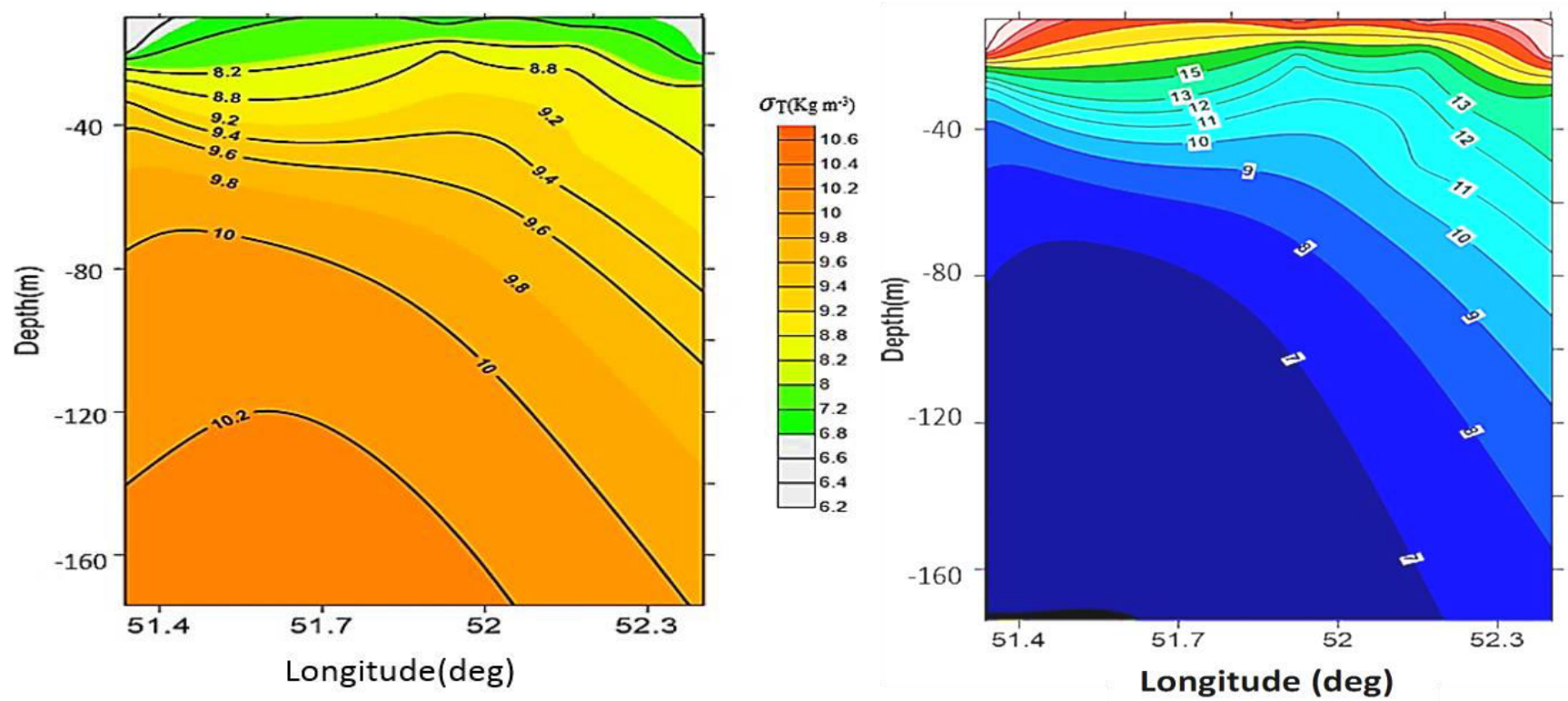

Figure 3: Observed density (left) and temperature (right) fields along transect B in summer, shown in Figure 1 right. 
Ocean Sci. Discuss., doi:10.5194/os-2016-87, 2017

Manuscript under review for journal Ocean Sci.

\subsection{Some general features of the COHERENS numerical model, and its boundary and initial conditions'}

COHERENS (Coupled Hydrodynamical Ecological model for Regional Shelf seas), which uses a vertical sigma coordinate and the hydrostatic incompressible version of the Navier-Stokes equations with Boussinesq approximation and equations of temperature and salinity, has been used (Luyten et al., 1999). The model uses an Arakawa C-grid (Arakawa and Suarez,

5 1983), and equations are solved numerically using the mode-splitting technique. The grid size in horizontal is $0.046 \times 0.046$ degrees, typically $5 \mathrm{~km}$, and 30 sigma levels, labelled $\mathrm{k}$ (the bottom layer is 1 and surface one is 30 ). The coastlines and bathymetry data with $0.5^{\prime} \times 0.5^{\prime}$ resolution are acquired from GEBCO, although interpolated and smoothed slightly.

The initialisation of the model was with January data; and it was forced by six hourly wind, acquired from ECMWF (Mazaheri et al., 2013), and air pressure and temperature with $0.5^{\circ} \times 0.5^{\circ}$ resolution acquired from the reanalyses (ERA-

10 Interim) ECMWF data, and precipitation rate, cloud cover and relative humidity $\left(2.5^{\circ} \times 2.5^{\circ}\right)$ were derived from NCEP/NCAR re-analysis data.

Typical numerical results of deep flows for the middle and southern basins of the Caspian Sea (the flow for the northern basin is not shown) for May and December of 2004, after four years of warm up of the model operation, are shown in Figure 4. The deep narrow flow in the northern basin and the overflow over the Absheron sill and in the north western boundary of

15 the southern basin are clearly observed.

As the northern shallow waters of the Caspian Sea are subjected to high evaporation in summer, in the following cold seasons these waters become dense and start to sink, mainly in the north eastern side (Gunduz and Özsoy, 2014), into the middle basin (see Figure 4 and 5). The flow due to its high density enters the deep part of the middle Caspian and starts to fill the middle Caspian Sea basin. After filling the middle Caspian basin, it appears to overflow into the southern basin. This

20 overflow enters the southern Caspian Sea through Absheron Strait. The topography has a strong effect on the deep basin flows (Shiea and Bidokhti, submitted for publication). From such results the parameters of the deep flow are derived. Shiea and Bidokhti also point to this narrow deep flow which is actually a part of the deep circulation in the Caspian Sea, although considered as an inviscid flow.

The deep flow seems to follow the bottom topography, indicating that the side deep slopes of the middle and southern and basins strongly influence the abyssal circulation. This in fact led us to propose an analytical model for the bottom sloped density current affected by bottom friction, hence spiralling into the deep parts of the southern Caspian Sea basin. Typical

Rossby number of this flow is about $R o=\frac{U}{f W}=0.2 /\left(10^{-4} \times 20 \times 10^{3}\right) \sim 0.1$ (here $U$ is typical speed of the overflow and $W$ is its width), which justifies the geostrophic nature (assumption) of the flow entering the southern basin. 
Ocean Sci. Discuss., doi:10.5194/os-2016-87, 2017

Manuscript under review for journal Ocean Sci.

Published: 11 January 2017

(c) Author(s) 2017. CC-BY 3.0 License.
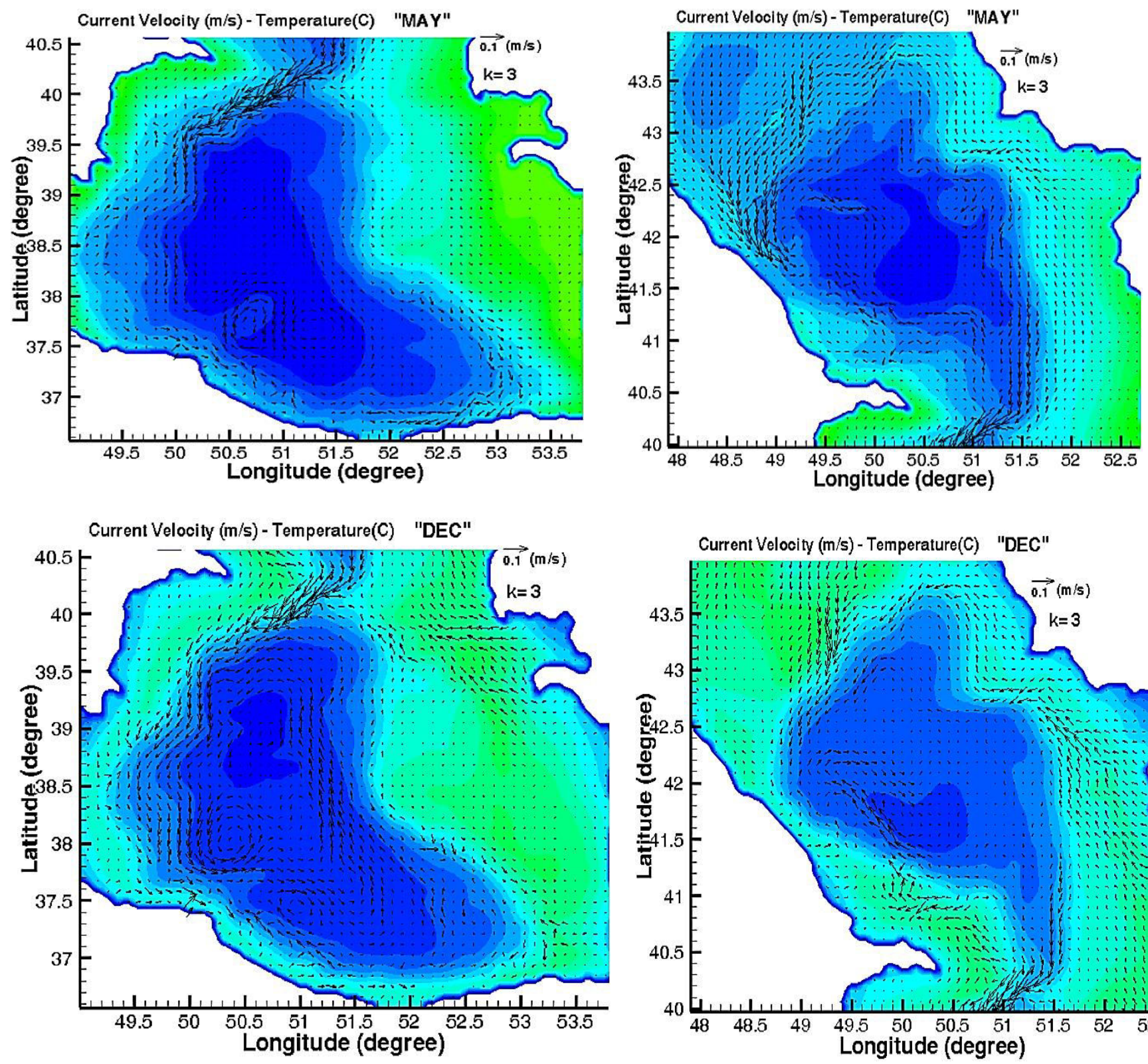

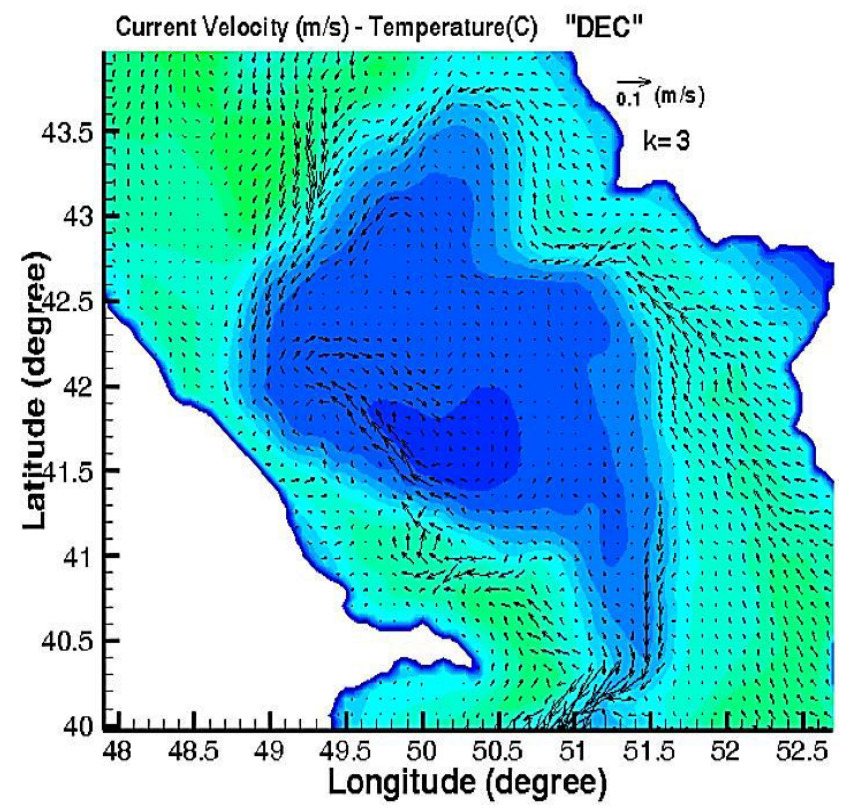

$\begin{array}{lllllllllllll}T: & 5 & 7 & 9 & 11 & 13 & 15 & 17 & 19 & 21 & 23 & 25 & 27\end{array}$

Figure 4: Monthly mean currents $(\mathrm{m} / \mathrm{s}$ ) in layer "k=3" (near the bottom) obtained from model simulations in southern (left) and middle (right) basins of the Caspian Sea for the months of May, December (2004). 
Ocean Sci. Discuss., doi:10.5194/os-2016-87, 2017

Manuscript under review for journal Ocean Sci.

Published: 11 January 2017

(c) Author(s) 2017. CC-BY 3.0 License.

Discussions

(c) (i)

\section{Dynamics of the overflow}

\section{1 An analytical model for the overflow in the Strait}

As the gravity current flows over the incline sill, it adjusts itself under the gravitational, rotational and frictional forces. The zonal and meridional components of momentum of the buoyancy driven current are given by assuming no pressure gradient;

5 a uniform dense flow under a less dense layer at rest; local coordinates $x^{\prime}$ is along the flow, northward, and $y^{\prime}$ is across it westward (see Figure 5); with no entrainments at its boundaries; under these simplifying assumptions, the continuity equation is trivial and hence, the required momentum equations for the solution are:

$$
\begin{aligned}
& \frac{d u^{\prime}}{d t}=-g^{\prime} \tan \theta+f v^{\prime}-r u^{\prime} \\
& \frac{d v^{\prime}}{d t}=-f u^{\prime}-r v^{\prime}
\end{aligned}
$$

where $u^{\prime}$ and $v^{\prime}$ are Lagrangian northward and westward local components of velocity respectively (as the solution is done this way, the components are different from that which are usually used, please see Figure 5), $f$ is the Coriolis parameter (= $2 \Omega \sin v$, where $\Omega$ is the earth angular speed, and $v$ is the latitude angle) and calculated as $f \sim 9.2 \times 10^{-5} \mathrm{~s}^{-1} . \theta$ is the bottom slope angle and here $\tan \theta=0.02, g^{\prime}$ is the reduced gravity, values of reduced gravity were calculated for different seasons (see table 1), $r$ is the bottom friction coefficient and values considered were $0.00001 \mathrm{~s}^{-1}$ and $0.00002 \mathrm{~s}^{-1}$. The solutions of these differential equations are as follows: (where $x^{\prime}$ and $y^{\prime}$ are Lagrangian location coordinates of the flow and $c_{1}$ and $c_{2}$ are constants to be found from boundary conditions, see Table 1 below).

$$
\begin{aligned}
& u^{\prime}(t)=c_{1} e^{-r t} \sin (f t)+c_{2} e^{-r t} \cos (f t)-\frac{g^{\prime} r \tan \theta}{f^{2}+r^{2}} \\
& v^{\prime}(t)=c_{1} e^{-r t} \cos (f t)-c_{2} e^{-r t} \sin (f t)+\frac{g^{\prime} f \tan \theta}{f^{2}+r^{2}} \\
& x^{\prime}(t)=\frac{f c_{2}-r c_{1}}{f^{2}+r^{2}} e^{-r t} \sin (f t)-\frac{f c_{1}+r c_{2}}{f^{2}+r^{2}} e^{-r t} \cos (f t)-\frac{g^{\prime} r \tan \theta}{f^{2}+r^{2}} t+\frac{f c_{1}+r c_{2}}{f^{2}+r^{2}} \\
& y^{\prime}(t)=\frac{f c_{1}+r c_{2}}{f^{2}+r^{2}} e^{-r t} \sin (f t)+\frac{f c_{2}-r c_{1}}{f^{2}+r^{2}} e^{-r t} \cos (f t)+\frac{g^{\prime} f \tan \theta}{f^{2}+r^{2}} t+\frac{r c_{1}-f c_{2}}{f^{2}+r^{2}}
\end{aligned}
$$

Where: 


$$
\begin{aligned}
& c_{1}=v_{p}-\frac{g^{\prime} f \tan \theta}{f^{2}+r^{2}} \\
& c_{2}=u_{p}+\frac{g^{\prime} r \tan \theta}{f^{2}+r^{2}}
\end{aligned}
$$

$u_{p}$ and $v_{p}$ are components of velocity when the gravity current just begins to flow over the inclined sill.

As the time passes, the flow tends to reach a steady state and moves parallel to the sloped bed. Then in this situation $v_{t \rightarrow \infty}^{\prime}$ and $u_{t \rightarrow \infty}^{\prime}$ are obtained from the following equation in which $\mu$ is the flow angle from zonal east-west direction.

$$
\begin{aligned}
& u_{t \rightarrow \infty}^{\prime}=-\frac{g^{\prime} r \tan \theta}{f^{2}+r^{2}}, v_{t \rightarrow \infty}^{\prime}=\frac{g^{\prime} f \tan \theta}{f^{2}+r^{2}} \\
& \tan \mu=\frac{u_{t \rightarrow \infty}^{\prime}}{v_{t \rightarrow \infty}^{\prime}}, \mu=\arctan \left(-\frac{r}{f}\right) \\
& \tan \lambda=\frac{u_{p}}{v_{p}}, \lambda=\arctan \left(\frac{u_{p}}{v_{p}}\right)
\end{aligned}
$$

As the flow develops with time it shows some oscillations with the local inertial period, and after a few inertial periods it acquires a steady state, moving with angle $\mu$ from which $u_{t \rightarrow \infty}^{\prime}$ and $v_{t \rightarrow \infty}^{\prime}$ are obtained using this angle and the flow speed. The analytical model input parameters (see Table 1 below) were determined from observations (cross-sections shown in Figure 3) and numerical simulations in the Strait of Absheron, from the cross-sections as shown in figure 6.

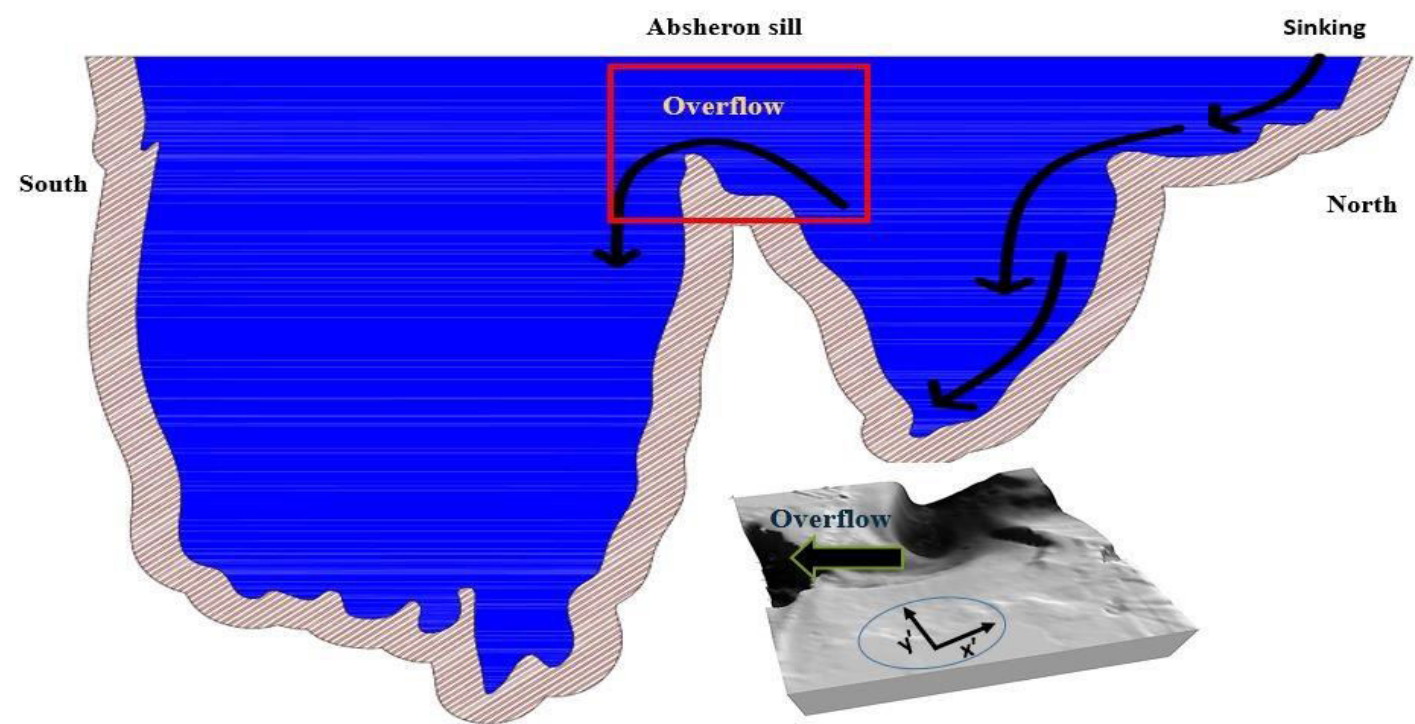

Figure 5: A schematic diagram of the sinking flow in the middle basin and the overflow current over Absheron sill (top), and topography around the sill in the middle of the Caspian Sea with the chosen coordinates (bottom). 

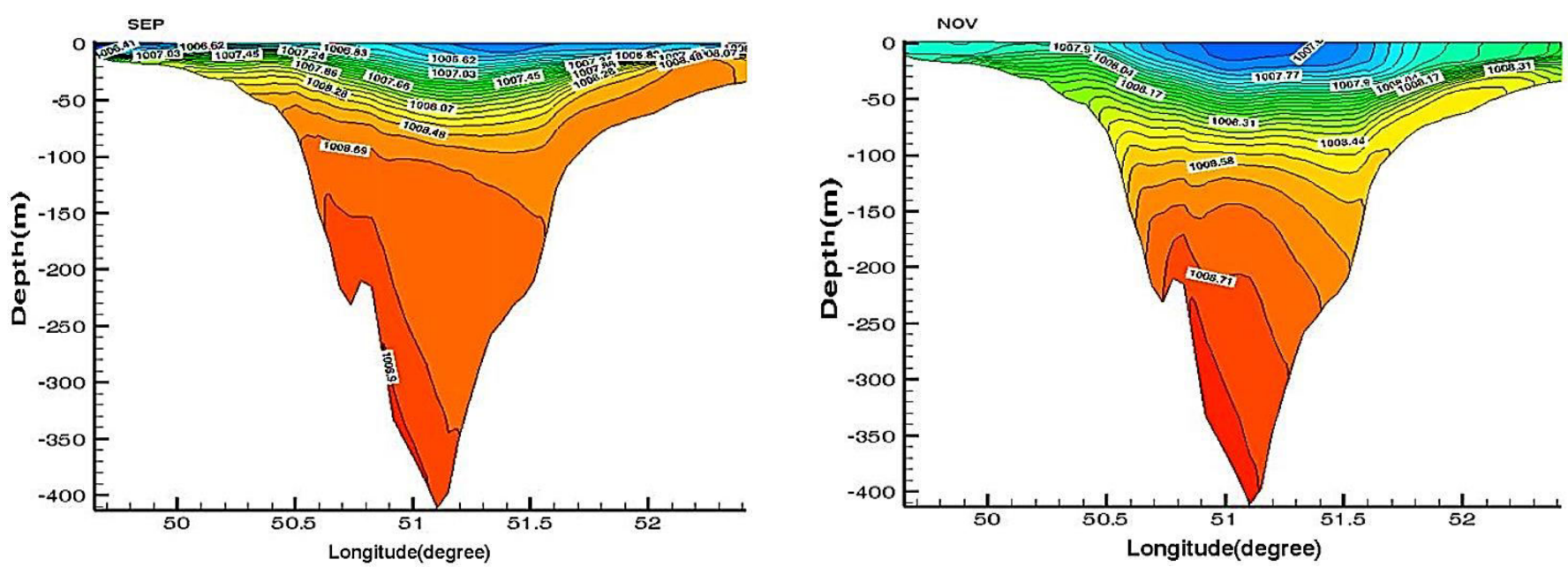

Figure 6: Observed density fields along transect C in Sept. and Nov. 2004.

\section{1. 1 The result of the analytical model}

15 Figure 7, 8, and 9 show that as the flow passes through the Strait, due to the Coriolis force it is diverted to the right. If initial velocity is greater, the effects of the Coriolis force will be less, so it moves farther along the meridian. According to the Rossby number of the flow ( $R o=\frac{U}{f W}$, here $U$ is typical speed of the overflow and $W$ is its width), when velocity increases the relative effect of Coriolis is also reduced. The results show that at later times (especially for larger drag coefficient) the flow moves a shorter distance in longitude and the direction of flow loses its sinusoidal and symmetric shape (Figure 9 and Table

20 1). According to Table 1, the angle between the velocity and horizontal is reduced when compared with the initial velocity. After an initial acceleration, the flow oscillates a few times before adjusting to a flow at a small angle to the isobaths, depending on the bottom friction coefficients (Figures 7, 8, and 9).
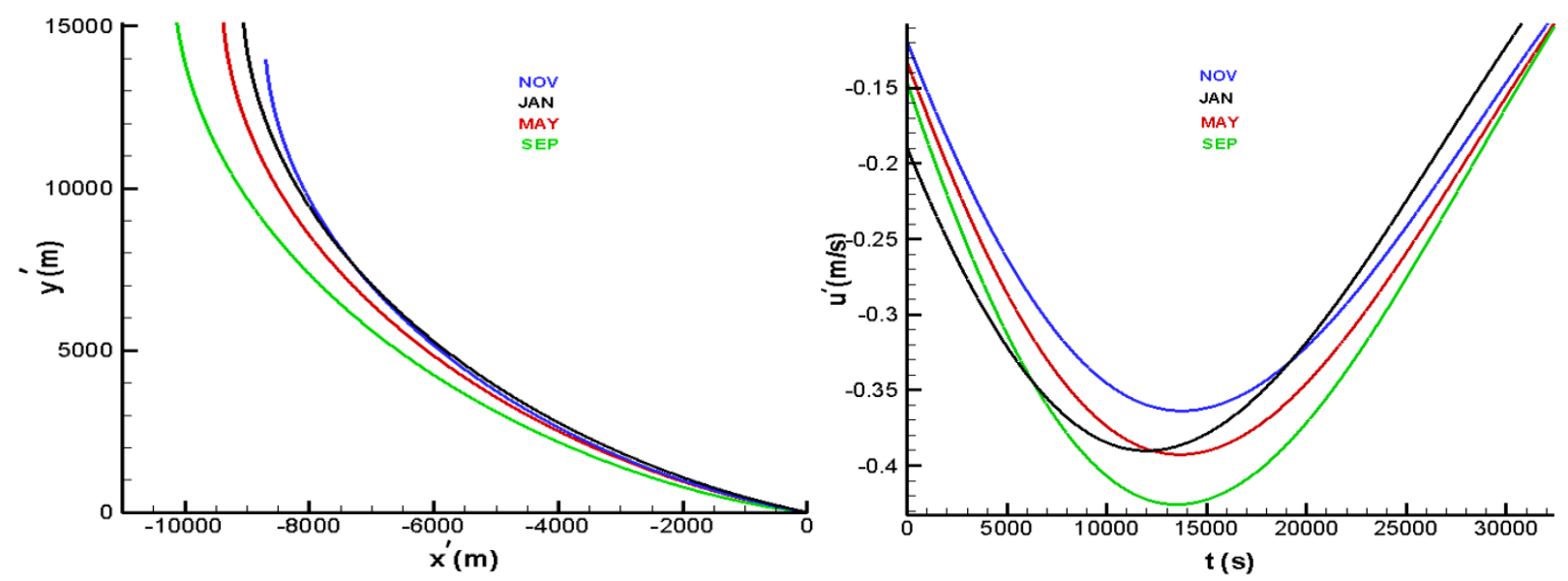

Figure 7: The initial paths (southwards, based on local coordinates used, see model descriptions above) and velocities of the flow for different conditions of different months after $t=9 h$. 
Ocean Sci. Discuss., doi:10.5194/os-2016-87, 2017

Manuscript under review for journal Ocean Sci.

Published: 11 January 2017

(c) Author(s) 2017. CC-BY 3.0 License.
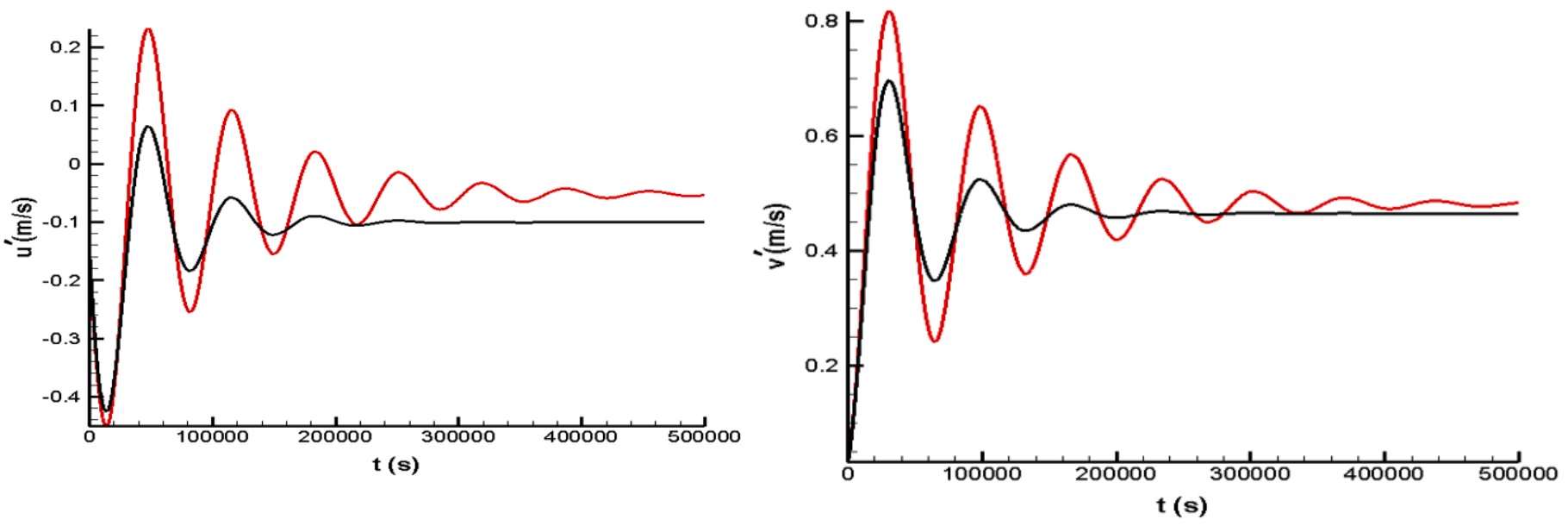

Figure 8: The comparison of the velocity components of flow with friction coefficient 0.00001 (red) and $0.00002 \mathrm{~s}^{-1}$ (black) in May (long-time).

15

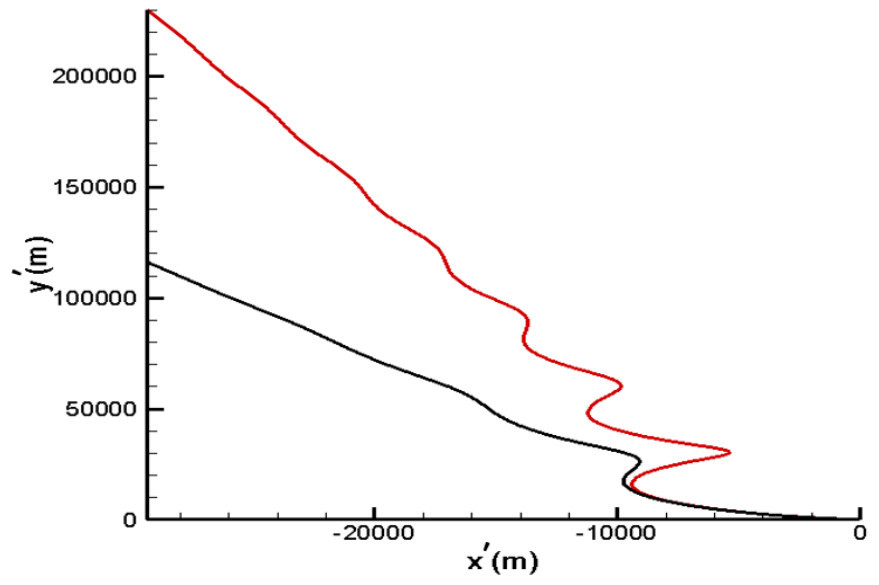

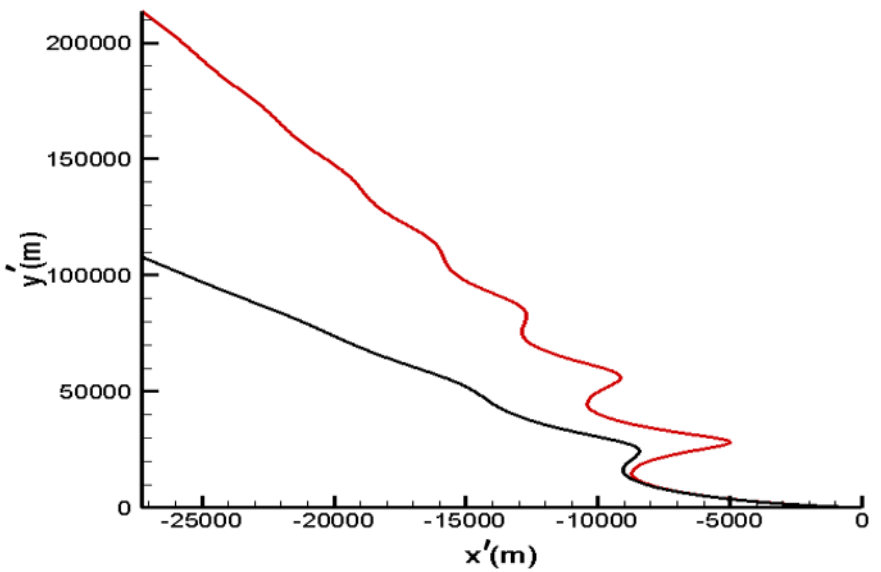

Figure 9: The comparison of the path of the flow with friction coefficient 0.00001 and $0.00002 \mathrm{~s}^{-1}$ in Jan (left) and Nov (right).

Table 1: Boundary current parameters and variables obtained from the numerical model (see text).

\begin{tabular}{lccccccc}
\hline & $\boldsymbol{g}^{\prime}\left(\mathbf{m} / \mathbf{s}^{2}\right)$ & $\boldsymbol{u}_{\boldsymbol{p}}(\mathbf{m} / \mathbf{s})$ & $\boldsymbol{v}_{\boldsymbol{p}}(\mathbf{m} / \mathbf{s})$ & $\boldsymbol{u}_{t \rightarrow \infty}^{\prime}(\mathbf{m} / \mathbf{s})$ & $\boldsymbol{v}_{t \rightarrow \infty}^{\prime}(\mathbf{m} / \mathbf{s})$ & $\boldsymbol{\mu}(\mathbf{d e g})$ & $\boldsymbol{\lambda}(\mathbf{d e g})$ \\
\hline NOV & 0.00222 & -0.12 & 0.044 & -0.046 & 0.43 & 6.1 & 69.86 \\
JAN & 0.00239 & -0.133 & 0.047 & -0.049 & 0.46 & 6.08 & 70.53 \\
MAY & 0.00251 & -0.147 & 0.031 & -0.052 & 0.48 & 6.18 & 78.09 \\
SEP & 0.00241 & -0.19 & 0.078 & -0.050 & 0.46 & 6.2 & 67.68 \\
\hline
\end{tabular}


Ocean Sci. Discuss., doi:10.5194/os-2016-87, 2017

Manuscript under review for journal Ocean Sci.

Published: 11 January 2017

(c) Author(s) 2017. CC-BY 3.0 License.

\section{2 A model for the trapped flow}

In this model, the structure of this flow is considered using an analytical model similar to that of Bidokhti and Ezam (2009) but with the bottom friction. As the flow enters the southern Caspian Sea basin, it adjusts into an internal Quasi-geostrophic flow with the assumption that the potential vorticity is conserved, because of topography in the South Caspian (see Figure

5 10). We can write:

$$
\frac{\xi+f}{h}=\text { cte }
$$

Here $\xi$ is the relative vorticity, $h$ is the upper layer thickness (depth of the flow from the surface) and $f$ is the Coriolis parameter. Constant value of potential vorticity, when the flow located on the Strait of Absheron is considered; $f_{0} / h_{0}$. $f_{0}$ and $h_{0}$ are respectively local Coriolis parameter and upper layer depth over the sill. When moving along the topography of the

10 sea sloped bed, the governing equations of steady flow (with no mixing that could exist due to flow entrainments near its boundaries and similar assumptions as for the analytical model above, see section 3.1) are as follows:

$$
\begin{aligned}
& f v=g^{\prime} \frac{\partial h}{\partial x}-r u \\
& -f u=g^{\prime} \frac{\partial h}{\partial y}-r v
\end{aligned}
$$

Where now $u$ and $v$ are respectively the eastward and southward velocity components (see Figure 10), $g^{\prime}$ is the reduced gravity, $r$ is the drag coefficient (considered $0.00001 \mathrm{~s}^{-1}$ and $0.00002 \mathrm{~s}^{-1}$ ), and $\partial h / \partial x, \partial h / \partial y$ are slopes of the isopycnals of the overflow, related to the pressure gradient. Equation (8) follows from (7) assuming $\partial h / \partial y<<\partial h / \partial x$ :

$$
\xi=\frac{g^{\prime}}{f+\frac{r^{2}}{f}} \frac{\partial^{2} h}{\partial x^{2}}
$$

After substituting Eq. (8) in Eq. (6), an equation for $h$ is obtained.

$$
\frac{\partial^{2} h}{\partial x^{2}}=\beta^{2} h-\gamma
$$


Ocean Sci. Discuss., doi:10.5194/os-2016-87, 2017

Manuscript under review for journal Ocean Sci.

Published: 11 January 2017

(c) Author(s) 2017. CC-BY 3.0 License.

(c) $\underset{\mathrm{BY}}{(i)}$

Where:

$$
\begin{gathered}
\beta^{2}=\left(\frac{f+\frac{r^{2}}{f}}{g^{\prime}}\right) \frac{f_{0}}{h_{0}} \\
\gamma=\left(\frac{f+\frac{r^{2}}{f}}{g^{\prime}}\right) f .
\end{gathered}
$$

The solution of $h$ equation is as follows which is also shown in Figure 10:

$$
h=c_{1} e^{\beta x}+c_{2} e^{-\beta x}+\frac{\gamma}{\beta^{2}}
$$

Where $c_{1}$ and $c_{2}$ are constants determined by the conditions that at the near-shore boundary $(x=0)$ and at a distance where $x$ derivative of $h$ is negligible $(x=R)$ the flow vanishes (see Figure 10, and Figure as 11 was used to derive values for these conditions); therefore, using these boundary conditions gives:

$$
c_{1}=c_{2}=c
$$

10 Hence, according to the equation, at $x=0, h_{1}=2 c+\frac{\gamma}{\beta^{2}}$ and at $x=R, h_{R}=c\left(e^{\alpha R}+e^{-\alpha R}\right)+\frac{\gamma}{\beta^{2}}$ then:

$$
R=\frac{1}{\beta} \cosh ^{-1}\left(\frac{h_{R}-\frac{\gamma}{\beta^{2}}}{h_{1}-\frac{\gamma}{\beta^{2}}}\right)
$$

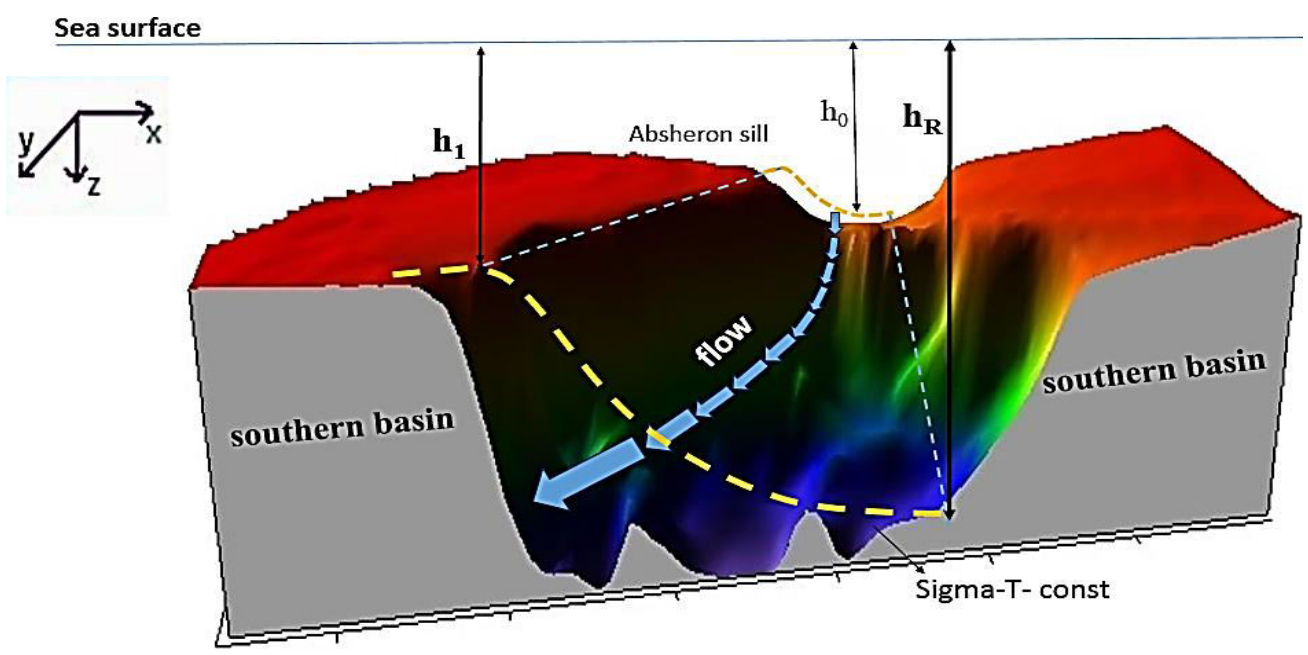

Figure 10: The parameters of the outflow model, a typical isopycnal surface is shown after the sill with corresponding $h$ values found from the density fields such as shown in Figure 11 (Axes are in right-hand coordinates). 

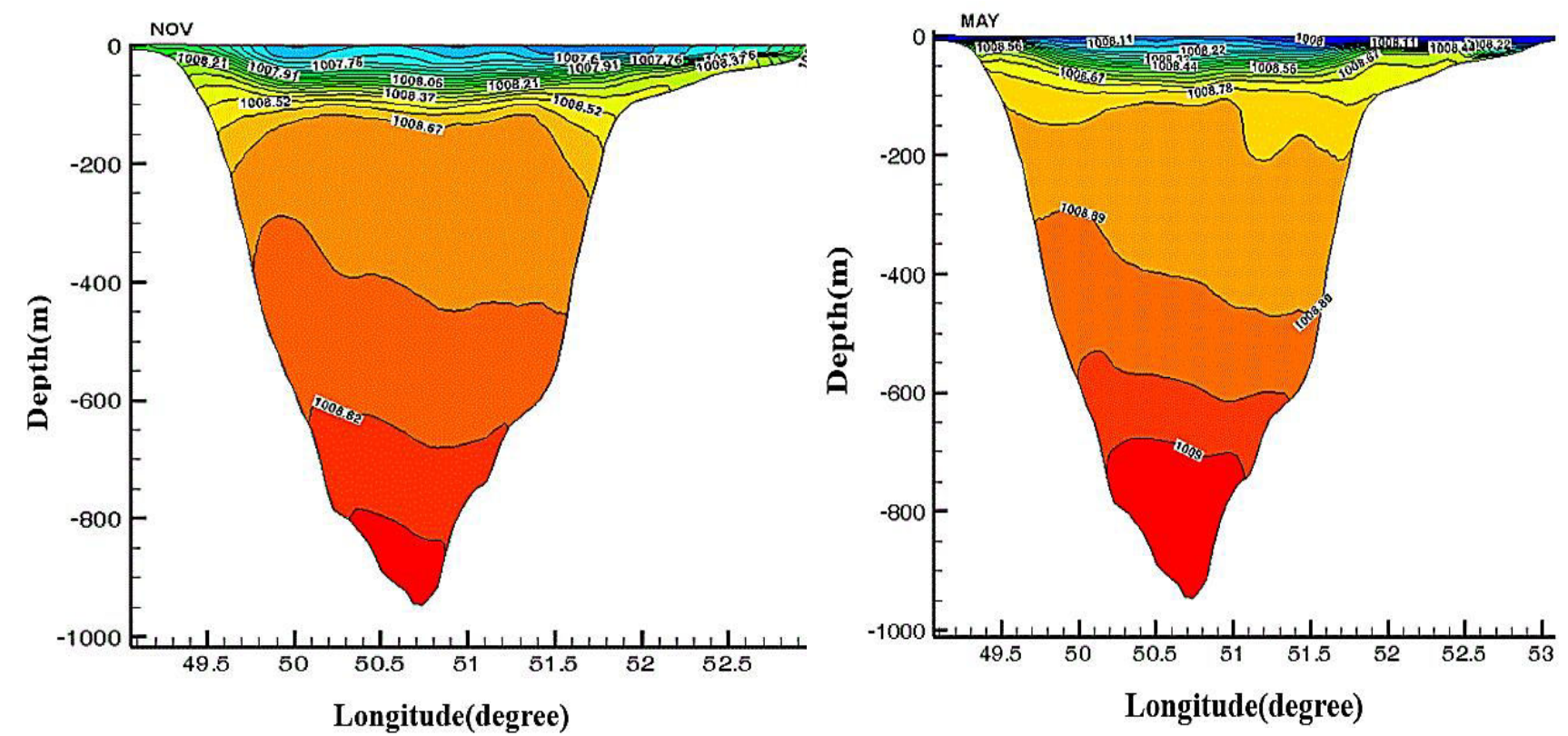

Figure 11: Density fields along transect D in May (left) and Nov. (right).

15

\subsection{The result of the analytical model}

This model is presented for the trapped flow after Absheron sill due to Coriolis effect. Results show that the Rossby deformation radius (length, $\sim \beta^{-1}$ ) or the effective width of the flow which depends on the drag coefficients and reduced gravity, varies for different seasons. The smallest and largest widths (Rossby lengths) of the flow are for November and September respectively. According to the results, this length decreases when drag coefficient increases. The estimated Rossby length of this model as compared to that of the Persian Gulf outflow shows that radius of deformation for the Persian Gulf outflow is about twice that of this overflow in the Caspian Sea. This is related to the fact that Caspian Sea is located at higher latitude with larger Coriolis effect (about 30 percent larger). Other parameters as $g^{\prime}$ and the flow depth are also important in determining the Rossby length of the trapped flow.

Table 2: Boundary trapped current model parameters (see Figure 10), $R_{l}$ and $R_{2}$ are respectively values of $\mathrm{R}$ for drag coefficients of $10^{-5} \mathrm{~s}^{-1}$ and $2 \times 10^{-5} \mathrm{~s}^{-1}$.

\begin{tabular}{llllll}
\hline & $\boldsymbol{h}_{\boldsymbol{0}}(\mathbf{m})$ & $\boldsymbol{h}_{\boldsymbol{I}}(\mathbf{m})$ & $\boldsymbol{h}_{\boldsymbol{R}}(\mathbf{m})$ & $\boldsymbol{R}_{\boldsymbol{I}}(\mathbf{m})$ & $\boldsymbol{R}_{\boldsymbol{2}}(\mathbf{m})$ \\
\hline NOV & 170 & 500 & 550 & 4565 & 4470 \\
JAN & 150 & 350 & 380 & 6221 & 6080 \\
MAY & 110 & 270 & 460 & 10530 & 10350 \\
SEP & 140 & 250 & 425 & 12520 & 12219 \\
\hline
\end{tabular}


Ocean Sci. Discuss., doi:10.5194/os-2016-87, 2017

Manuscript under review for journal Ocean Sci.

Published: 11 January 2017

(c) Author(s) 2017. CC-BY 3.0 License.

\section{3 Flushing times and the volumes of dense water calculations}

In this section, as we derive the parameters of the overflow, a relation is presented for the calculation of the abyssal volume flow rate between the two basins of the Caspian Sea via the Absheron Strait. This is given by (12) in which $v$ is the mean magnitude of geostrophic velocity of the overflow and $d A$ is its cross section area.

$$
Q_{V}=\int v d A
$$

Due to the parabolic form of the bottom topography of Absheron Strait, its geometry of the dense overflow in this valley like shape (Figure 12) can be given by:

$$
\begin{aligned}
& \mathrm{Y}=a x^{2}+b x+c \\
& h=A e^{-\alpha x}
\end{aligned}
$$

Where $a, b, c, A$, and $\alpha$ are assumed to be constant. Due to the fact that $Y$ and $h$ in graph (Figure 12) are from $L_{1}$ to $L_{2}$ we can calculate $h$ and $Y$ values at $\left(x=L_{1}\right)$ and $\left(x=L_{2}\right)$, Substituting Eq. (13) in Eq. (12) and using these assumptions and that $v$ is given by the slope of $\mathrm{h}$ in $\mathrm{x}$ direction, we have:

$$
Q_{V}=\frac{g^{\prime}}{f} \frac{H_{1}-H_{2}}{L_{2}-L_{1}}\left[\left(-\frac{A}{\alpha}\left(e^{-\alpha L_{2}}-e^{-\alpha L_{1}}\right)-\frac{a}{3}\left(L_{2}^{3}-L_{1}^{3}\right)-\frac{b}{2}\left(L_{2}^{2}-L_{1}^{2}\right)\right]\right.
$$

Where:

$$
a=\frac{H_{2} L_{1}+H_{1} L_{2}}{L_{1}\left(L_{2}^{2}+L_{1} L_{2}\right)}
$$

$$
b=\frac{H_{2} L_{1}+H_{1} L_{2}}{L_{2}^{2}+L_{1} L_{2}}-\frac{H_{1}}{L_{1}}
$$

If we assume that $L_{1}=L_{2}=L$, we have

$$
Q_{V}=\frac{g^{\prime}}{f} \frac{H_{1}-H_{2}}{L_{2}-L_{1}}\left[\frac{2 A}{\alpha} \sinh (\alpha L)-\frac{2}{3} a L^{3}\right]
$$


Ocean Sci. Discuss., doi:10.5194/os-2016-87, 2017

Manuscript under review for journal Ocean Sci.

Published: 11 January 2017

(c) Author(s) 2017. CC-BY 3.0 License.

Discussions

(c) $\underset{\mathrm{BY}}{(i)}$

Where:

$$
\begin{aligned}
& a=\frac{H_{2}+H_{1}}{2 L^{2}} \\
& b=\frac{H_{2}-H_{1}}{2 L} \\
& A=\frac{H_{1}}{e^{\alpha L}} \\
& \alpha=-\frac{1}{2 L} \operatorname{Ln} \frac{H_{2}}{H_{1}}
\end{aligned}
$$

To calculate the mean monthly volume flow rate of the deep current that enters the southern basin of the Caspian Sea, we

5 assume that its density is greater than $1008.78 \mathrm{~kg} / \mathrm{m}^{3}$, the average density (for different seasons) of the flow upper boundary (e.g. Figure 13) and use equation (15) and Figure 13 for this purpose.

For the times that the middle and southern basins are filled, first the volumes of middle $\left(V_{M}\right)$, and southern $\left(V_{S}\right)$ basins (see Figure12) below three levels $(z=0, z=-100$, and $z=-150 \mathrm{~m}$, the approximate depth of the Absheron sill that is more appropriate only for southern basin) are calculated, then if we assume the same annual mean value $Q_{V}$ for both basins, these filling times are estimated. The results of these calculations and comparisons between them in different seasons are given in Tables 3 and 4. The results show that the maximum and minimum flow rates of abyssal water that enter the Southern Caspian Sea are in May and November respectively.

15
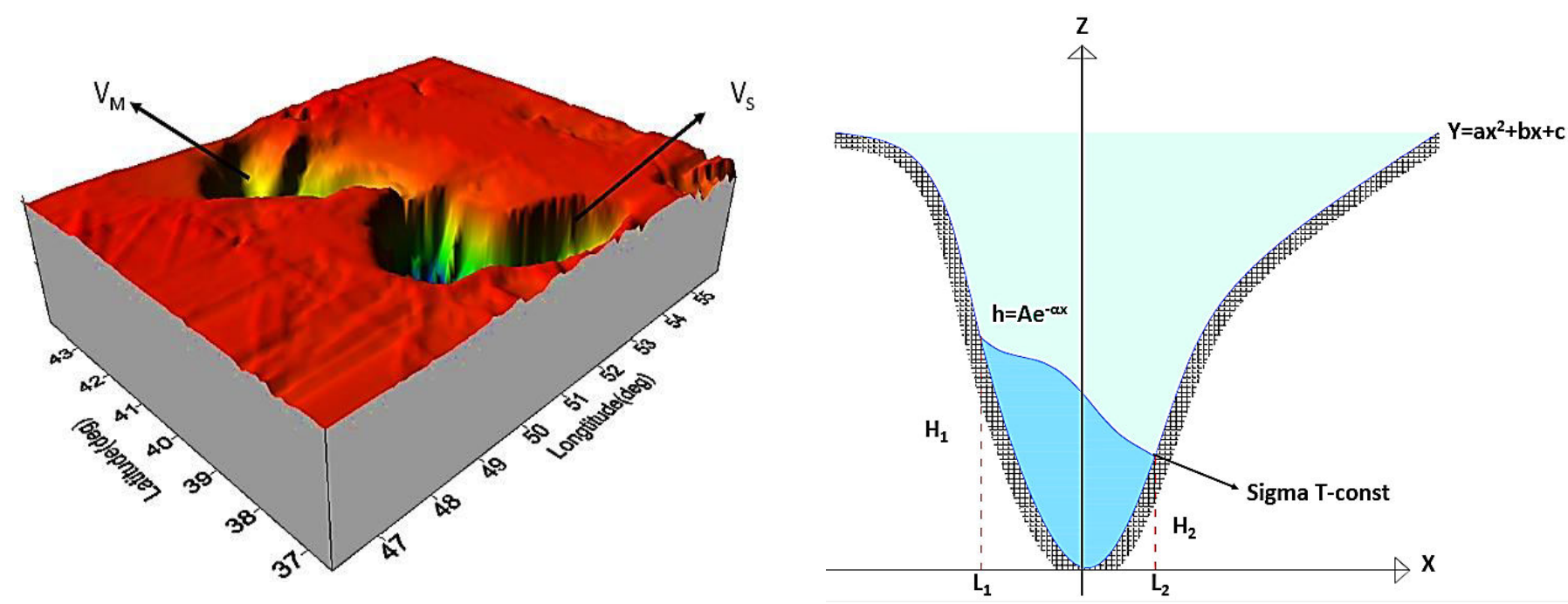

25 Figure 12: The modeling bathymetry used and the scheme of the topography with a typical isopycnal and model parameters. 

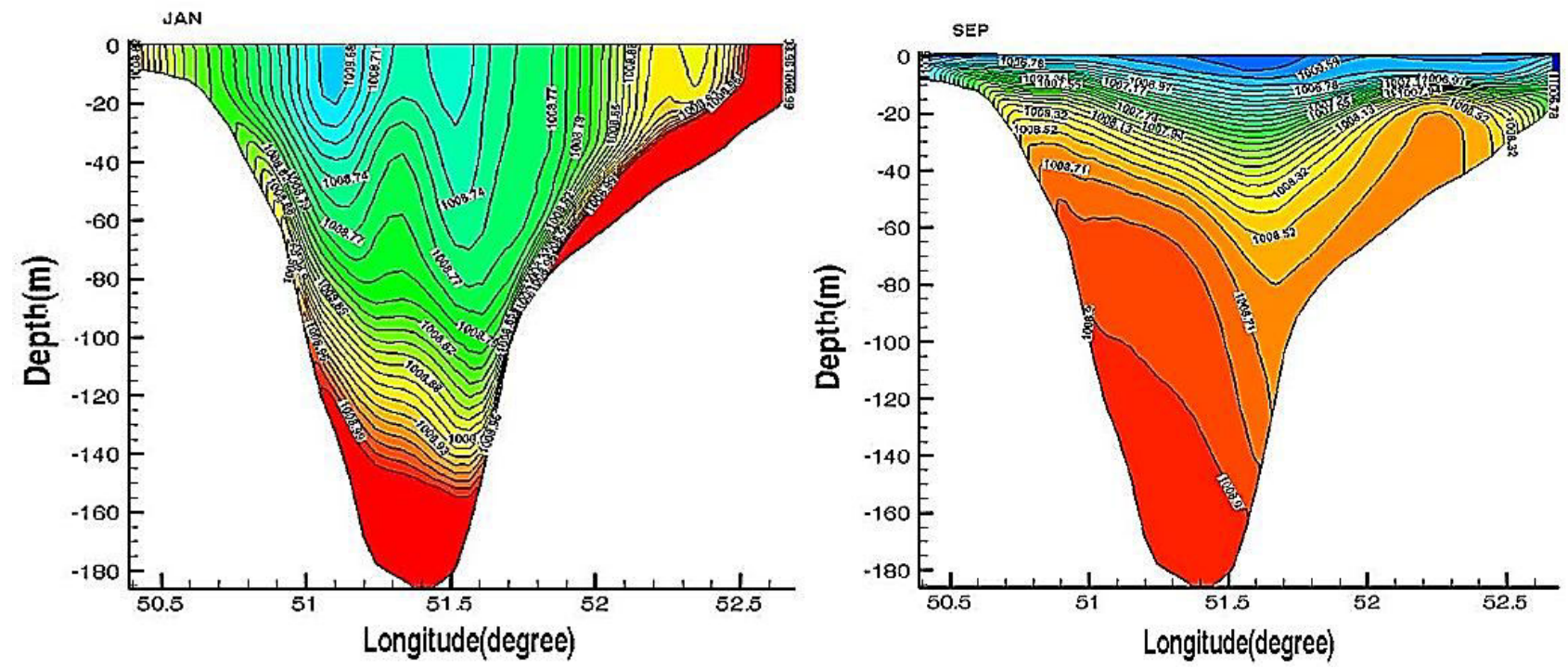

Figure 13: Typical density fields along transect A for Jan. (left) and Sept. (right) from which we calculate the flow rates.

Table3: The model boundary current parameters $\left(1 \mathrm{~Sv}=10^{6} \mathrm{~m}^{3} / \mathrm{s}\right)$ for different months.

\begin{tabular}{lcccc}
\hline & $\boldsymbol{H}_{\boldsymbol{I}}(\mathbf{m})$ & $\boldsymbol{H}_{\mathbf{2}}(\mathbf{m})$ & $\boldsymbol{L}(\mathbf{m})$ & $\boldsymbol{Q}_{\boldsymbol{V}}(\mathbf{S v})$ \\
\hline NOV & 55 & 10 & 19000 & 0.016 \\
JAN & 145 & 85 & 32000 & 0.115 \\
MAY & 145 & 55 & 34000 & 0.146 \\
SEP & 135 & 45 & 27500 & 0.116 \\
\hline
\end{tabular}

Table 4: Flushing times of the middle $\left(T_{M}\right)$ and the southern $\left(T_{S}\right)$ basins (using an annual average volume flow rate, $Q_{v}$ ) below three levels.

\begin{tabular}{lcccc}
\hline Level & $\begin{array}{c}V_{M} \\
\left(\mathbf{m}^{\mathbf{3}} \times \mathbf{1 0}^{\mathbf{1 3}}\right)\end{array}$ & $\begin{array}{l}\boldsymbol{V}_{S} \\
\left(\mathbf{m}^{\mathbf{3}} \times \mathbf{1 0}^{\mathbf{1 3}}\right)\end{array}$ & $\boldsymbol{T}_{M}($ year $)$ & $\boldsymbol{T}_{S}$ (year $)$ \\
\hline $\boldsymbol{Z = 0}$ (sea surface) & 2.55 & 5.12 & 8.35 & 16.77 \\
$\mathbf{Z = - 1 0 0}$ & 1.09 & 4.13 & 3.57 & 13.5 \\
$\mathbf{Z = - 1 5 0}$ & 0.36 & 3.62 & 1.17 & 11.85 \\
\hline
\end{tabular}


Ocean Sci. Discuss., doi:10.5194/os-2016-87, 2017

Manuscript under review for journal Ocean Sci.

Published: 11 January 2017

(c) Author(s) 2017. CC-BY 3.0 License.

\section{Conclusions}

The results of observations and numerical simulations showed that there is an abyssal flow from the middle to the southern

5 basins of the Caspian Sea. The density difference between the deeper water of the middle basin and that of southern basin leads to an overflow gravity current over the Absheron sill. This difference is mainly due to the temperature difference between deeper parts of these two basins, as a result of cold water initially sinking in the northern part of this Sea, at about 48 degrees latitude, that fills first the middle basin and then overflows towards the southern basin. In the autumn and winter, surface water cools, its density is increased and then sinks to the deep part of the middle basin, as the deep convection

10 process in high latitude oceans. Winter storms and cold wind provide the cooling of this rather high-latitude shallow water in the northern basin.

Analytical models for the gravity driven flow over the sloped bed of the Absheron sill, and that of subsequent trapped flow, were used to estimate typical mass transport and flushing times of the deep water basins of this Sea. The model for the gravity driven flow over a sloped bed has inertial, Coriolis and frictional forces included. In its initial stage the flow has

15 some oscillations of inertial type with typical local inertial period at this latitude. After this varying behaviour, the flow adjusts itself moving south as a gravity driven topographically trapped current, spiralling into deeper parts due to bottom friction. It always tends to move toward the western shores of this Sea, mainly due to the Coriolis force that shifts it to the right. Such flow is important in the abyssal circulation and ventilation of the deep southern basin of the Caspian Sea. The model for the determining Rossby length of the flow showed that it varies for different seasons. Also when drag coefficient

20 increases, this length decreases. Results showed that nearly $3.05 \times 10^{12} \mathrm{~m}^{3}$ of water per year by this abyssal flow enters the Southern basin giving a typical flushing time of about 15 years. Hence, the Southern Caspian basin ecosystem is strongly dependent on this flow.

The northern and middle Caspian Sea basins have become important areas for oil and gas explorations (especially the Absheron shallow Strait area) and marine transport nowadays. Since the Caspian Sea is an enclosed sea, the adverse effects

25 of such activities may particularly affect the deep part of these Caspian Sea basins. For this reason, it is recommended that more detailed observational data are collected in the deep parts of the southern and middle basins of the Caspian Sea, by joint projects with neighbouring countries. More extensive and high resolution observational data and numerical simulations are required to find more details of the outflow structure over and around the Absheron sill (Strait) and the deeper parts of this Sea basins. 
Ocean Sci. Discuss., doi:10.5194/os-2016-87, 2017

Manuscript under review for journal Ocean Sci.

Published: 11 January 2017

(c) Author(s) 2017. CC-BY 3.0 License.

\section{References}

Arakawa A. and Suarez M.J., 1983. Vertical differencing of the primitive equations in sigma coordinates. Monthly Weather 5 Review, 111, 34-45.

Aubrey, D.G., Glushko, T.A., Ivanov, V.A., 1994. North Caspian Basin: Environmental status and oil and gas operational issues, Report for Mobil-oil, 650 pages.

Aubrey, D.G., 1994. Conservation of biological diversity of the Caspian Sea and its coastal zone. A proposal the Global

10 Environment Facility, Report to GEF, 250 pages.

Baringer, M. O., and Price, J. F., 1997. Mixing and spreading of the Mediterranean outflow: Journal of Physical Oceanography, 27, 1654- 1677.

Bidokhti, A. A. and Ezam, M., 2009. The structure of the Persian Gulf outflow subjected to density variations, Ocean Sci., 5, 1-12, doi: 10.5194/os-5-1-2009.

15 Britter, R. and Linden, P., 1980. The motion of the front of a gravity current travelling down an incline. J. Fluid Mech. 99, $531-543$.

Dickson, R. R., Gmitrowics E. M., and Watson A. J., 1990. Deep water renewal in the northern North Atlantic, Nature, 344, 848-850.

Ellison, T. H. and Turner, J. S., 1959. Turbulent entrainment in stratified flows. J. Fluid Mech. 6, $423-448$.

20 Fogelqvist, E., Blindheim, J., Tanhua, T., Østerhus, S., Buch, E., and Rey, F., 2003. Greenland-Scotland overflow studied by hydro-chemical multivariate analysis. Deep-Sea Res. I, 50(1): 73-102.

Girton, J. B., and T. B. Sanford., 2003. Descent and modification of the overflow plume in the Denmark Strait, J. Phys. Oceanogr., 33, 1351-1364.

Griffiths, R. W., 1986. Gravity currents in rotating systems. Ann. Rev. Fluid Mech. 18, 59-89.

25 Gunduz, M., Özsoy, E., 2014. Modelling Seasonal Circulation and Thermohaline Structure of the Caspian Sea. Ocean Science., 11, 259-292.

Ismailova, B. B., 2004. Geoinformation modeling of wind-induced surges on the northern eastern Caspian Sea, Math. Comput. Simulat., 67, 371-377.

Luyten, P.J., Jones, J.E., Proctor, R., Tabor, A., Tett, P., and Wild-Allen, K., 1999. COHERENS- A coupled 30 hydrodynamical-ecological model for regional and shelf seas: user documentation, MUMM Rep., Management Unit of the Mathematical Models of the North Sea.

Mazaheri, S., Kamranzad, B., Hajivalie, F., 2013. Modification of 32 years ECMWF wind field using QuikSCAT data for wave hindcasting in Iranian Seas. J. Coastal Research, Special Issue No. pp., 344- 349. 
Ocean Sci. Discuss., doi:10.5194/os-2016-87, 2017

Manuscript under review for journal Ocean Sci.

Published: 11 January 2017

(c) Author(s) 2017. CC-BY 3.0 License.

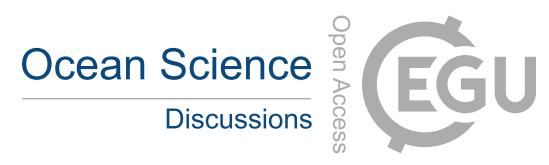

(c) (i)

Shiea, M. and Bidokhti, A. A., 2016. A numerical study of the abyssal water circulation in the Caspian Sea. Submitted to Journal of Continental Shelf Research.

Smith, P.C., 1975. A streamtube model for bottom boundary currents in the ocean. Deep-Sea Res. 22, 853873. 